\section{Effects of deprivation on the tongue flicking and orientation of young rat snakes to water*}

\author{
MICHAEL S. LOOP \\ Florida State University, Tallahassee, Fla. 32306
}

Young rat snakes (Elaphe) were deprived of water for 6 days and then tested by placing a dry cotton swab and a swab dipped in distilled water $1 \mathrm{~cm}$ in front of the snake's snout. Two measures, approach/tongue flick and approach orientation, revealed that the water elicited higher responding than the dry stimulus. The Ss were then tested over a 10-day period. The stimulating effectiveness of water under deprivation was found to decline at first and then increase until ad lib water was returned. It was concluded that water is an effective stimulus for the snake's chemoreceptors but would elicit responding only under conditions of deprivation.

Burghardt (1967a, b, 1968, 1969) and Morris \& Loop (1969) have investigated the effects of various prey-object extracts on the attack/tongue-flick behavior of newborn snakes. All of these studies have employed distilled water as the control stimulus and have made the consistent observations that water (1) never elicits an attack, and (2) almost invariably elicits the lowest number of tongue flicks. Burghardt (1969) has extended the analysis of the response to water to observe "a definite, although by no means highly consistent, decrease" over trials on successive days. The most prominent decrease occurred between the first and second trial on the same day. The question logically arises, why does water, presumably of survival value to all snakes examined, elicit such low response scores? Two alternatives are possible: (1) Water is not an effective stimulus for the snake's chemoreceptors (when presented on a swab) or (2) water is not effective unless the snake is water deprived. Allen \& Neill (1959) stated that a snake sometimes will not find a water pan in its cage but will drink if its nose is placed near the surface of the water. They go on to suggest that, "The snake's flickering tongue apparently identifies the water." While their conclusions are based on extensive observation of snakes in captivity, the data is nonetheless anecdotal. Crawford \& Loop (1967) employed water as a reinforcer in an operant situation in which adult Elaphe were required to interrupt a beam of light to obtain a $5-\mathrm{sec}$ exposure to water. They employed deprivation levels of 5,6 , and 7 days and suggested that the drinking behavior of Elaphe in the absence of food was cyclical,

*This work was supported in part by Psychobiology Research Center, Florida State University, through USPHS Grant NB-7468, NSF Grant GU-2612, and NIH Grant, EY-00594 to Mark Berkley. Thanks are extended to $S$. Rosen and $\mathrm{C}$. Hall for assistance. with a period of once every 3 to 4 days. The present study was undertaken to investigate the effects of deprivation on the stimulating effectiveness of water.

\section{EXPERIMENT 1 Method}

The Ss $(N=6)$, age 9 months, were the offspring of an interrace mating between a female Elaphe obsoleta obsoleta from Eastern Tennessee and a male Elaphe obsoleta quadrivittata from Southern Florida. Ss were housed in separate containers and had taken part in previous similar studies.

The Ss were tested once each on a blank (dry) swab and a swab dipped in distilled water following 6 days of food and water deprivation. Swab presentations were counterbalanced; intertrial interval was $30 \mathrm{~min}$. On a given trial a swab, either dry or dipped in distilled water, was placed $1 \mathrm{~cm}$ in front of the $S$ 's snout. If the $S$ touched the swab, it was counted as an approach. If the S did not touch the swab within $30 \mathrm{sec}$, the swab was moved slowly forward until it touched the S's snout and then moved back to $1 \mathrm{~cm}$. A single trial lasted $60 \mathrm{sec}$, during which the number of tongue flicks was counted and the time of the first tongue flick away from the swab was noted. If an approach was made, the trial was terminated and the latency was recorded to the nearest second.

The effectiveness of stimulation by the water and the blank swab was evaluated with two measures. The first was Burghardt's formula, which has thus far been the sole response measure in any of the studies involving this general methodology. This formula is the maximum number of tongue flicks emitted by any $S$ to any stimulus, plus the length of a single trial, minus the latency of approach (attack) in seconds. If no approach occurred, the number of tongue flicks was taken as the stimulating value of the swab. The second measure stems from the observation that in previous experiments the length of time the $S$ spent oriented toward the swab seemed to correlate with the attack/tongue-flick behavior elicited by that prey-object extract. This measure was designated as orientation time. The orientation time was defined as the time between the first tongue flick and the first tongue flick which fell at least $2 \mathrm{~cm}$ away from the swab. This first tongue flick away from the swab was invariably preceded by a sharp turning of the head, leaving little to subjective judgment. If an approach was observed, the orientation time was taken as $60 \mathrm{sec}$ (maximum possible in any trial without an attack) plus $60 \mathrm{sec}$ minus the latency of approach. This formula is very similar to Burghardt's, with the maximum possible orientation time without an approach (i.e., trial duration) substituted for the maximum number of tongue flicks without approach. If no approach occurred, the time between the first tongue flick and the first tongue flick away from the swab was taken as the orientation time. Results

During the course of the experiment, three approaches were made to the water (mean latency $6 \mathrm{sec}$ ), none to the blank swab. Figure 1 presents the a p proach/tongue-flick and approach-orientation time measures. The blank swab produced almost identical scores for the two measures, 30.0 and 31.3 for approach/tongue flick and approach-orientation, respectively. The water elicited greater scores for both
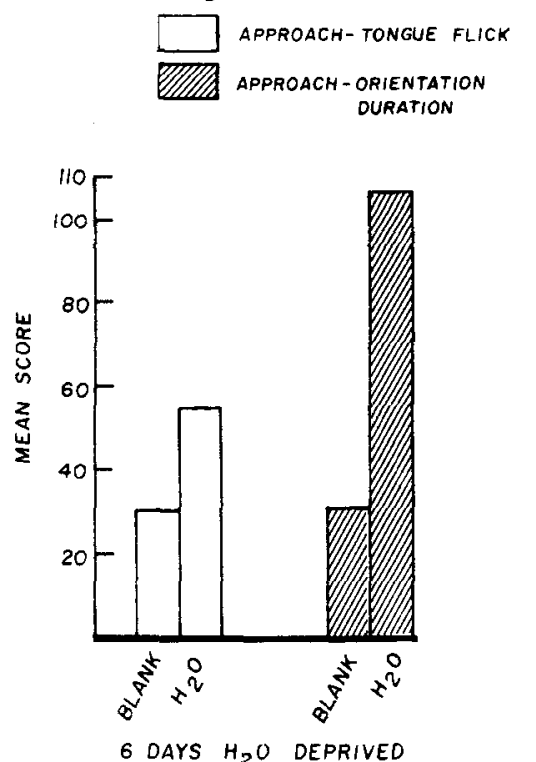

Fig. 1. Approach/tongue-flick and approach-orientation scores for a blank and water stimuli, following 6 days of water deprivation. 


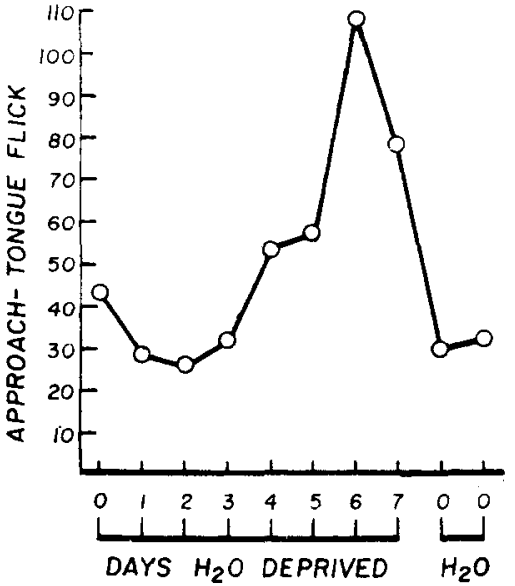

Fig. 2. Approach/tongue flick as a function of days water deprived.

measures: 54 for approach/tonge flick and 107 for approach-orientation. A Wilcoxon signed-rank test found the approach/tongue-flick difference unreliable $(\mathrm{p}>.05)$, but the approach-orientation difference was reliable $(p=.03)$. These results demonstrated that water was distinguishable from a dry swab and answers the first question raised. A second experiment was then undertaken to investigate the possibility that deprivation was the controlling factor.

\section{EXPERIMENT 2}

Method

The Ss $(\mathrm{N}=8)$ were the same as those employed in the first experiment plus two additional individuals from the same litter. They were 1-week food deprived at the beginning of the study. Water was removed from their individual cages on the first experimental day and was returned following testing on the eighth day. The room was constantly illuminated with fluorescent light throughout the study. The Ss were tested once daily and trial length was increased to $90 \mathrm{sec}$. response measure of approach/tongue flick and approach orientation was calculated in the same manner with increased trial length taken into account in the approach-orientation measure.

\section{Results}

During the 80 trials, 15 approaches were observed. All of these approaches were confined to Days $4,5,6$, and 7 of deprivation, with mean latencies of 64.6 $(\mathrm{n}=3), 27.6(\mathrm{n}=3), 29.2(\mathrm{n}=5)$, and $29.3 \mathrm{sec}(n=4)$, respectively. For the remaining 65 trials, the number of tongue flicks for a single trial ranged from 0 (three trials) to $78 \mathrm{sec}$ (two trials). The orientation time ranged from 0 (three trials) to $90 \mathrm{sec}$ (nine trials). The mean approach/tongue-flick scores as a function of days water deprived are presented in Fig. 2. The approach/tongue-flick score showed an initial drop between the first and second day, as was observed by Burghardt (1969), between Trials 1 and 2 within the same day. This initial drop in the approach/tongue-flick score was followed by 3 days of consistently low responding. An increase was observed in the fourth day of deprivation that was maintained until the seventh day, with the highest score occurring on the sixth day of deprivation. A sharp drop in approach/tongue-flick scores was coincidental with the return of ad lib water to the Ss. Figure 3 presents the approach-orientation time as a function of days of water deprivation.

The approach-orientation scores showed an initial increase from the first to the second day with a subsequent decrease through the third day of deprivation. An increase occurred on the fourth day of deprivation which was maintained, at a relatively constant level, through the seventh day of deprivation. The sharp decrease in approach-orientation scores was, again, coincidental with the return of water to the Ss. A Friedman multi-sample test for rank-order differences was employed to evaluate the main effects of water deprivation. Both approach/tongue-flick $(p<.05)$ and approach-orientation $(p<.01)$ differences were reliable. A Kendall's test for correlation revealed a coefficient of rank correlation of .62 between the approach/tongue flick and approach-orientation that was marginally reliable $(\mathrm{p}=.1)$.

The mean weight of the Ss prior to water deprivation was $23.0 \mathrm{~g}$. Mean weight on Day 7 of water deprivation was $20.5 \mathrm{~g}$. Return of ad lib water resulted in an increase of mean body weight to $21.7 \mathrm{~g}$ within $24 \mathrm{~h}$.

\section{DISCUSSION}

It is clear. from the data of both experiments that the mere presentation of the swab was sufficient to elicit some responses. It would appear, however, that water is an effective stimulus for the snake's chemoreceptors and will elicit high responding if the snake is water deprived. In no instance was an approach not preceded by several tongue flicks and, in most instances, jaw movements reminiscent of those seen during actual drinking occurred before the snake actually made contact with the swab.

Earlier studies generated two a priori predictions. The data of Burghardt (1969) predicted an initial decrease in responsiveness to water with repeated presentations, the most pronounced decrease occurring between the first and second trials. As can be seen in Fig. 2, the

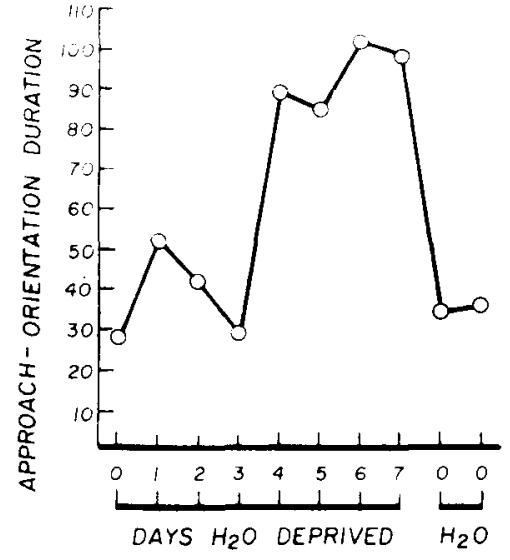

Fig. 3. Approach-orientation as a function of days water deprived.

approach/tongue-flick scores for the first 4 days meet this prediction perfectly. The operant studies of Crawford \& Loop (1967) predicted that the effects of water deprivation should begin to appear between Days 3 and 4 . Both measures show that a sharp increase did occur on the fourth day of water deprivation. A third prediction, dictated by logic, was that the return of ad lib water should reduce the effectiveness of water as a stimulus. This was indeed the case, for. the a p proach/tongue -flick and approach-orientation scores following the return of water are virtually identical to the score on the third day, which presumably represents the habituated response level prior to deprivation showing its effects on Day 4 of deprivation.

It is clear from the relatively high coefficient of rank correlation between the a p proach/tongue-flick and approach-orientation scores that the two measures are reflecting similar changes in the snakes' behavior. There are, however, some interesting differences. First of all, the approach-orientation measure showed a much sharper increase on the fourth day of deprivation, the first day of approaches. This sharp increase was then maintained at a surprisingly constant level until water was returned. The approach/tongue-flick scores, while also increasing on the fourth day, seemed to be much more influenced by the number of approaches occurring on a given day. It is the author's opinion that the stability of the approach-orientation score is the result of (1) employing a base unit that is equivalent for each $S$, i.e., the length of a trial, and (2) employing two time measures as opposed to combining a time and a frequency measure as in Burghardt's formula. The only major disc.upancy between the two measures occurred on the second experimental day with the approach/tongue flick showing a 
decrease while the approach-orientation score increased. Whether this represents a real difference or is experimental error remains to be determined. It would seem, however, that the approach-orientation measure may be a useful one for further research into the chemically mediated behavior of snakes.

\section{REFERENCES}

ALLEN, R, \& NEILL, W. T. Keep them alive. Silver Springs, 1'a.: Special Publication No. 1, 1959. P. 10.

BURGHARDT, G. M. Chemical perception in newborn snakes. Psychology Today, 1967a, 1, $50-59$.
BURGHARDT, G. M. Chemical-cue preferences of inexperienced snakes: Comparative aspects. Science, 1967b, 157, 718-721.

BLRGHARDT, G. M. Chemical preference studies on newborn snakes of three sympatric species of Natrix. Copeia, 1968, 4, 732-737.

BURGHARDT, G. M. Comparative prey-attack studies in newborn snakes of the genus Thamnophis. Behaviour, 1969, XXXIII, 1-2, 77-114.

CRAWFORD, F. T., \& LOOP, M. S. Operant rate of snakes under water deprivation: Preliminary studies. Psychonomic Bulletin, 1967, 1, 36.

MORRIS, D. D., \& LOOP, M. S. Stimulus control of prey attack in naive rat snakes: A species duplication. Psychonomic Science, 1969, 15, 141-142.
The Ss were trained in automatic shuttleboxes that have been described elsewhere (Brush, 1962). The CS was an increase in illumination and presentation of a 78-dB white noise in the compartment occupied by the rat. The US was a scrambled ac electric shock of $0.3 \mathrm{~mA}$, delivered through a series resistance of 750 kilohms. On each trial, printing counters recorded the number of intertrial responses and the latency $( \pm 0.1 \mathrm{sec})$ of the first response after CS onset.

\section{PROCEDURE}

All Ss received 10 pretest trials in which the CS was presented alone. On each trial a shuttle response terminated the CS or, if no response occurred, it terminated automatically after $45 \mathrm{sec}$. Animals that responded with latency less than $5 \mathrm{sec}$ on 5 or more of the 10 pretest trials or on 3 or more of the last 5 pretest trials were rejected. In addition to the animals included in the experiment, seven were rejected by this criterion. During the pretest the intertrial interval was $2 \mathrm{~min}$.

Immediately following the 10 pretest trials, the intertrial interval was shifted to $1 \mathrm{~min}$, and independent groups of 12 animals each received $0,5,15$, or 25 escape training trials in which the CS.US interval was $0.5 \mathrm{sec}$. Although the avoidance contingency was in effect during this time, no animal successfully avoided shock during this phase of training. Upon completion of this phase of the experiment, the animals were removed to their home cages for $5 \mathrm{~min}$, during which time food and water were available ad lib. They were then returned to the same apparatus and received 60 trials of avoidance training in which the CS-US interval was $5 \mathrm{sec}$.

\section{RESULTS AND DISCUSSION}

Figure 1 presents the median escape latency, measured from shock onset, as a function of trials during signaled escape training. In calculating these data, the data from groups that received 5, 15, and 25 trials were pooled, since the groups did not differ. The data for the first five trials, therefore, are based on 36 animals, for Trials 6-15 on 24 animals, and for Trials $16-25$ on 12 animals. The pattern of escape latency is quite similar to that reported earlier from data extracted from avoidance training, suggesting that the length of the CS-US interval on escape trials does not particularly alter the magnitude or pattern of escape latency. The latencies in this experiment, however, are much closer to those of the learners than the nonlearners of the previous experiment (Brush, 1966), As noted before, the increase in escape latency 